\title{
Insights acerca do uso de finos de carvão vegetal para geração de bioenergia
}

\author{
Fabíola Martins Delatorre ${ }^{1 *}$, Gabriela Fontes Mayrinck Cupertino ${ }^{1}$, Alfredo José dos Santos Junior ${ }^{1}$, Álison \\ Moreira da Silva ${ }^{1}$, Ananias Francisco Dias Júnior ${ }^{1}$, Maria Paula Reggiane Silveira ${ }^{1}$
}

\begin{abstract}
RESUMO: O carvão vegetal é um material altamente friável quando submetido ao impacto, parte se transforma em finos, fato considerado um problema para a maioria dos sistemas produtivos. Assim, este estudo teve como objetivo investigar a utilização de finos de carvão vegetal para fins energéticos, analisando a sua produção em três temperaturas finais de pirólise $\left(400,600\right.$ e $\left.800^{\circ} \mathrm{C}\right)$, a fim de gerar subsídios para uma melhor aplicabilidade do material. O material que foi homogeneizado em peneiras de 270 mesh, teve determinada a sua densidade aparente, densidade verdadeira, teores de materiais voláteis, de cinzas e de carbono fixo, poder calorífico superior, inferior e útil, densidade à granel e densidade energética. Constatou-se que os finos obtidos da pirólise a $800^{\circ} \mathrm{C}$ apresentou melhor potencial energético, uma vez que a elevação de temperatura contribuiu para maiores percentuais de carbono fixo e densidade energética. Esses resultados demostraram que os finos de carvão vegetal possuem potencial para utilização energética.
\end{abstract}

Palavras-chave: biomassa, reaproveitamentos de resíduos, friabilidade do carvão vegetal

\section{Insights about the use of charcoal fines for bioenergy generation}

\begin{abstract}
Charcoal is a highly friable material when subjected to impact, part of which becomes fines, a fact considered a problem for most production systems. Thus, this study aimed to investigate the use of charcoal fines for energy purposes, analyzing its production in three final pyrolysis preparations $\left(400,600\right.$ and $\left.800^{\circ} \mathrm{C}\right)$, in order to generate subsidies for better applicability of the material. The material that was homogenized in 270 mesh sieves, had its apparent density, true density, volatile material, ash and fixed carbon content, superior, inferior and useful calorific power, bulk density and energy density. It was found that the fines obtained from pyrolysis at $800^{\circ} \mathrm{C}$ have better energy potential since the elevation of temperature contributed to higher percentages of fixed carbon and energy density. These results demonstrated that charcoal fines have the potential for energy use.
\end{abstract}

Keywords: biomass, waste recycling, charcoal friability

\section{INTRODUÇÃO}

O carvão vegetal é amplamente empregado no setor energético de países em desenvolvimento, tendo destaque desde o seu uso como combustível aquecedor, até como principal fonte de abastecimento das indústrias siderúrgicas de alguns países. A sua produção mundial é de cerca de 52 milhões de toneladas por ano (FAO, 2016; KIRUKI et al., 2019). Cerca de $11 \%$ dessa produção está concentrada no Brasil, maior produtor mundial de carvão vegetal, com produção anual estimada em 6 milhões de toneladas (EPE, 2019; IBÁ, 2019). Impulsionado pelas indústrias e pelo setor energético, uma vez que representa $19 \%$ da matriz energética brasileira, o mercado de carvão vegetal cresce anualmente no país, sendo considerado um segmento consolidado (MME, 2019). Mesmo se destacando no mercado nacional, para que o carvão vegetal seja uma alternativa sustentável e economicamente viável algumas características físicas e químicas do produto devem

\footnotetext{
${ }^{1}$ Universidade Federal do Espírito Santo

* Email: fabiolamdelatorre@ hotmail.com
}

ser levadas em consideração, a fim de obter maior rendimento do material.

A friabilidade do carvão vegetal é sua capacidade de se fragmentar em pedaços, e assim, constitui uma característica física e intrínseca do material que proporciona uma elevada perda de rendimento final. Dentro do processo de fabricação, manuseio e transporte são produzidos cerca de 25 a $30 \%$ de finos, material esse proveniente da friabilidade do carvão vegetal (SOMERVILLE et al., 2015). Os finos podem ser injetados nas ventaneiras dos altos fornos de carvão ou simplesmente acumulados no pátio da carvoaria. Em geral esse material é descartado no meio ambiente sem tratamento prévio, podendo culminar em impactos ambientais, econômicos e sociais negativos (SIQUEIRA, 2015; RODRIGUES et al., 2019). Nesse contexto, estudos evidenciam a necessidade de recuperação e reutilização desses finos, uma vez que apresentam considerável potencial energético (DIAS JÚNIOR et al., 2015). 
Com a finalidade de favorecer uma melhor destinação dos finos de carvão vegetal, avaliar as características químicas, físicas e energéticas do material são essências para uma aplicação tecnicamente e economicamente viável (REIS et al., 2012; PROTÁSIO et al., 2014; MARTINS et al., 2016). Dessa forma, este estudo teve como objetivo investigar as propriedades físicas e químicas dos finos de carvão vegetal em três diferentes temperaturas finais de pirólise, a fim de subsidiar a sua utilização para fins bioenergéticos.

\section{METODOLOGIA}

Os finos de carvão vegetal foram obtidos a partir da madeira de Eucalyptus sp., com sete anos de idade no momento do corte. A madeira passou pelo processo de moagem em moinho de facas e inserido na estufa tipo mufla, onde foi pirolisado em três temperaturas finais de pirólise $\left(400,600\right.$ e $\left.800^{\circ} \mathrm{C}\right) \mathrm{sob}$ uma taxa de aquecimento de $10^{\circ} \mathrm{C} \mathrm{min}^{-1}$, com tempo de permanência de $120 \mathrm{~min}$. Posteriormente passouse o material no moinho de bolas, modelo MA-500, obtendo uma granulometria média de 270 mesh $(0,053 \mathrm{~mm})$.

A densidade aparente e verdadeira dos finos de carvão vegetal foi estabelecida de acordo com a norma NBR 9165 (ABNT, 1985). A obtenção do teor de materiais voláteis, teor de cinzas e teor de carbono fixo foi determinado por meio da norma D-1762-84 (ASTM, 2007). Determinou-se o poder calorífico superior (PCS) em uma bomba calorimétrica isotérmica marca IKA C200, em que os procedimentos foram realizados com base na norma NBR 8633 (ABNT, 1984). Para determinação do poder calorífico inferior (PCI) foi utilizado o modelo matemático presente na Equação 1, considerando percentual médio de hidrogênio $(\mathrm{H})$ presente no carvão vegetal de 6\% (BRITO, 1993).

$$
P C I=P C S-600 * \frac{9 H}{100} \quad(\text { Equação } 1)
$$

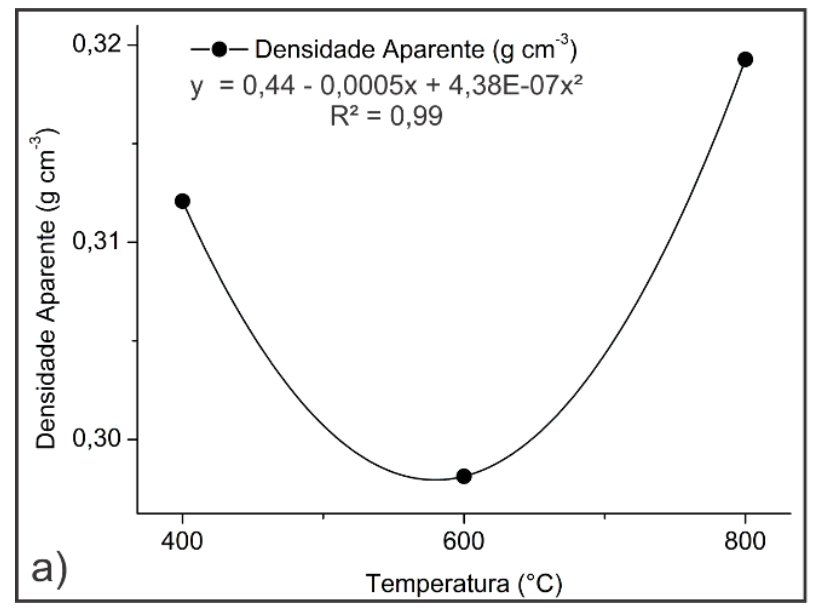

Em que: $\mathrm{PCI}=$ Poder calorífico Inferior; $\mathrm{PCS}=$ Poder calorífico superior; $\mathrm{H}=$ percentual de hidrogênio presente no material (adotado 6\%) (BRITO, 1993).

$\mathrm{O}$ poder calorífico útil (PCU) foi estimado com base na Equação 2, sugerida por Vale et al. (2000), que considera um dado teor de umidade (U), coletado seguindo a norma D1762-84 (ASTM, 2007).

$$
P C U=P C I(1-U)-600 U \quad(\text { Equação } 2)
$$

Em que: PCU $=$ Poder calorífico útil; $\mathrm{PCI}=$ Poder calorífico Inferior; $\mathrm{U}=$ Umidade.

Foi determinada a densidade à granel com base na norma NBR 6922 (ABNT, 1981) e com algumas adaptações para a matéria-prima finos. Para a determinação da densidade energética, realizou-se a multiplicação do poder calorífico útil (PCU) pela densidade à granel, seguindo a metodologia descrita por Andrade (2017).

Os dados foram submetidos às análises de estatística descritiva (médias, desvio padrão e coeficientes de variação) para cada temperatura de pirólise, além da análise de variância. Quando identificadas diferenças significativas ( $p$-valor $<0,5$ ), realizou-se o ajuste de modelo de regressão. Determinou-se o coeficiente de correlação de Pearson entre os resultados de densidade à granel, poder calorífico útil, densidade energética e teores de materiais voláteis, cinzas e carbono fixo, os quais foram submetidos à matriz de correlação.

\section{RESULTADOS E DISCUSSÕES}

Os resultados da Figura 1 mostram que a densidade aparente e densidade verdadeira do carvão vegetal. Ambas densidades tiveram comportamento semelhante, diminuindo inicialmente com o aumento da temperatura até $550^{\circ} \mathrm{C}$, mas depois aumentando com a temperatura de pirólise de $800^{\circ} \mathrm{C}$, característica semelhante encontrado por Dias Júnior et al. (2020).

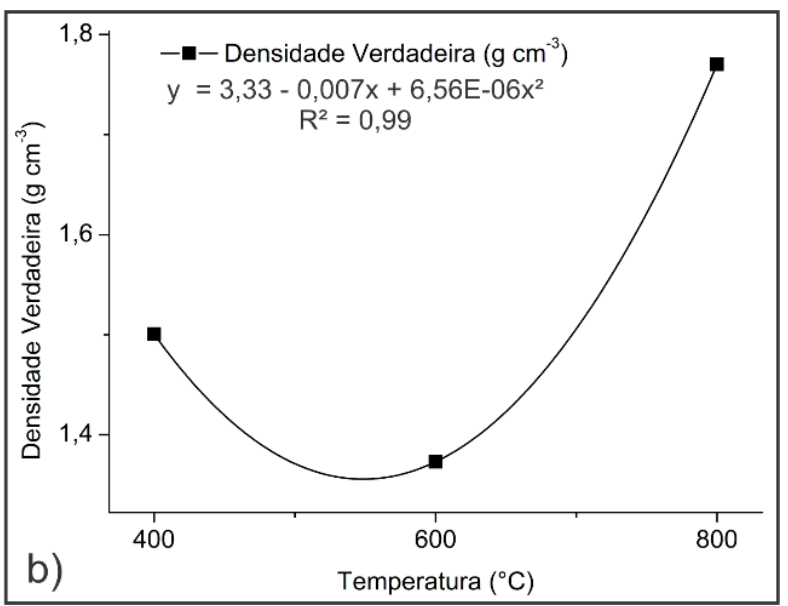

Figura 1 - Efeito da temperatura de pirólise na densidade aparente (a) e densidade verdadeira (b). 
Trugillho, Silva (2001) e Dias Júnior et al. (2020) afirmam que a perda de massa ocasionada pela liberação de materiais voláteis entre as temperaturas de $300^{\circ} \mathrm{C}$ a $500^{\circ} \mathrm{C}$ é muito maior do que a redução nas dimensões volumétricas do carvão vegetal, o que explica a diminuição da densidade aparente e verdadeira. Contudo, após $600^{\circ} \mathrm{C}$, a perda de massa é menor do que a contração devido à volatilização do $\mathrm{H}_{2}$, que possui baixa massa molecular. Além disso, para quebrar as ligações tipo $\mathrm{H}-\mathrm{H}$, requer grandes quantidades de energia, o que contribui para a diminuição acentuada da perda de massa em altas temperaturas de pirólise (TRUGILHO; SILVA, 2001; FIGUEIREDO et al., 2018; DIAS JÚNIOR et al., 2020). A densidade do carvão vegetal é uma propriedade física muito relacionada à madeira usada como matéria prima no processo de pirólise, temperatura e velocidade do processo (SILVA et al., 2018). Dessa forma, o comportamento da densidade dos finos de carvão obtidos nas diferentes temperaturas foram distintos. A temperatura de $800^{\circ} \mathrm{C}$ apresentou valores de densidade relativa verdadeira $\mathrm{e}$ aparente superior quando comparado às demais, sendo esses 1,77 e 0,32 g. $\mathrm{cm}^{-3}$, respectivamente. Valores similares ao encontrado por Reis et al. (2012) para Eucalyptus urophylla e Dias Júnior et al. (2020) para Eucalyptus saligna. Segundo Vale et al. (2010), a densidade aparente do carvão vegetal deve ser a maior possível para que esses combustíveis apresentem alta resistência mecânica e elevada densidade energética, assim, menores custos relacionados ao transporte. A densidade relativa verdadeira aumenta com elevação de temperatura de pirólise, o que pode ser justificado pela queda de matérias voláteis e aumento do teor de carbono fixo (OLIVEIRA et al., 2010). A densidade é uma importante propriedade da madeira e deve ser considerada no seu uso como combustível, pois se relaciona diretamente com a produção de energia, ou seja, quanto maior a densidade, maior a quantidade de energia estocada por unidade de volume (PROTÁSIO et al., 2014).

Os resultados dos teores de carbono fixo, materiais voláteis e cinzas são apresentados na Figura 2.

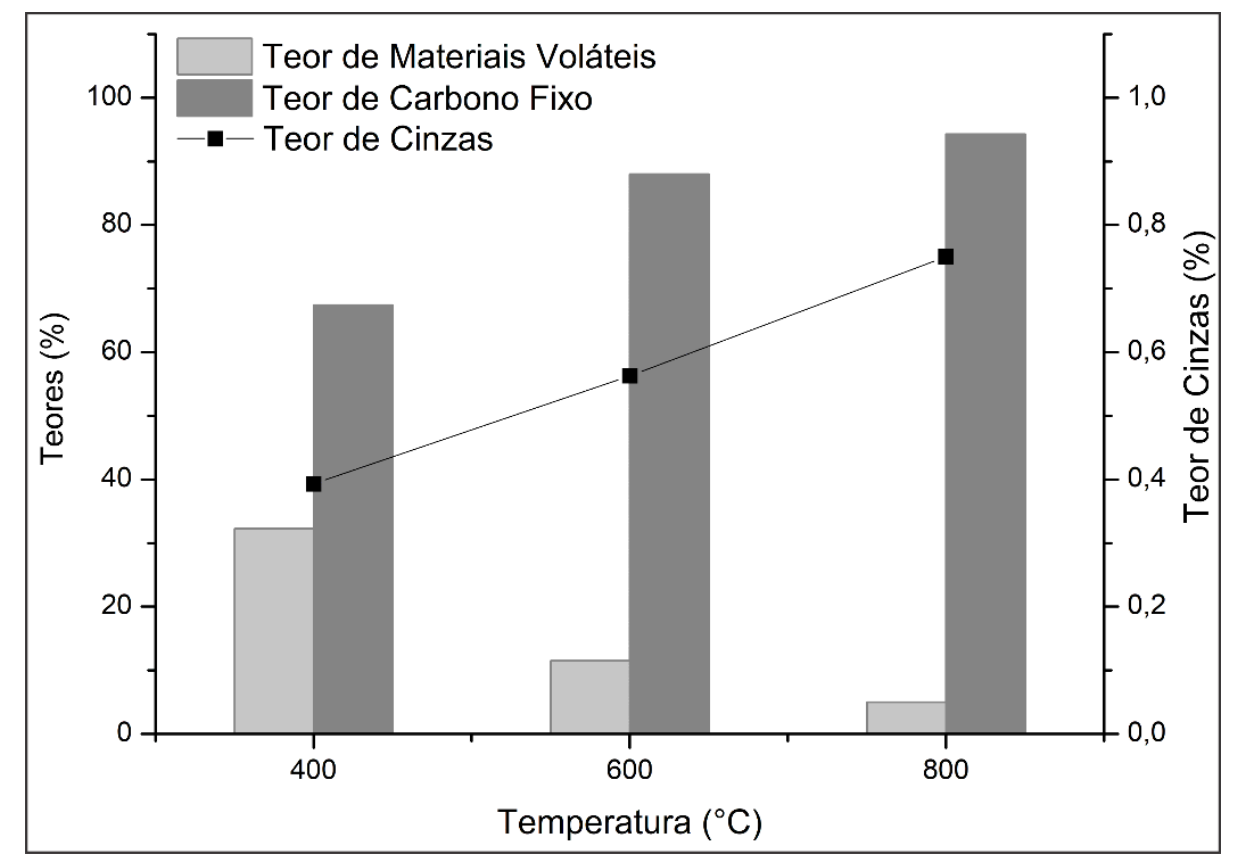

Figura 2 - Comportamento dos teores de materiais voláteis, carbono fixo e cinzas dos finos de carvão vegetal em três temperaturas finais de pirólise.

O conteúdo de materiais voláteis diminuíram nas composições com maiores temperaturas de pirólise, tendo uma redução de $27 \%\left(400\right.$ a $\left.800^{\circ} \mathrm{C}\right)$ do seu teor. A pirólise causa intensa degradação térmica dos constituintes químicos da madeira, principalmente do teor de extrativos, o que favorece a grande liberação de gases voláteis em temperaturas mais elevadas (WANG et al., 2017). Com comportamento inversamente proporcional ao de materiais voláteis, ao analisar os teores de carbono fixo dos finos de carvão vegetal, observa-se que houve uma elevação na concentração, passando de $67 \%$ a $400^{\circ} \mathrm{C}$ para $94 \%$ a $800^{\circ} \mathrm{C}$. As proporções relativas de materiais voláteis/carbono fixo são essenciais para a recomendação de biomassas para geração de calor, pois influenciam a combustibilidade e facilitam a ignição dos combustíveis (PROTÁSIO et al, 2019; DIAS JÚNIOR et al., 2020; DELATORRE et al., 2020). Ao se analisar o teor de cinzas do material estudado, observa-se que houve um pequeno aumento do seu percentual com a elevação de temperatura de pirólise, comportamento similar ao encontrado por Figueiredo et al. (2018). A utilização de elevadas temperaturas finais no processo de pirólise favorecem 
o aumento da concentração de minerais devido à perda de massa, contribuindo para maiores teores de cinzas (KLINGENBERG et al., 2020). Mesmo com essa elevação, o teor de cinzas obtido nos finos de carvão vegetal pode ser considerado baixo, se comparado aos relatados na literatura para Eucalyptus spp. carvão, geralmente < $1 \%$ (DIAS JÚNIOR et al., 2020; DELATORRE et al., 2020). Vassilev, Vassileva (2016), relataram que as cinzas formadas durante a combustão da biomassa resultam em alguns problemas tecnológicos e ricos ambientais importantes. Contudo, deve-se dar ênfase ao baixo

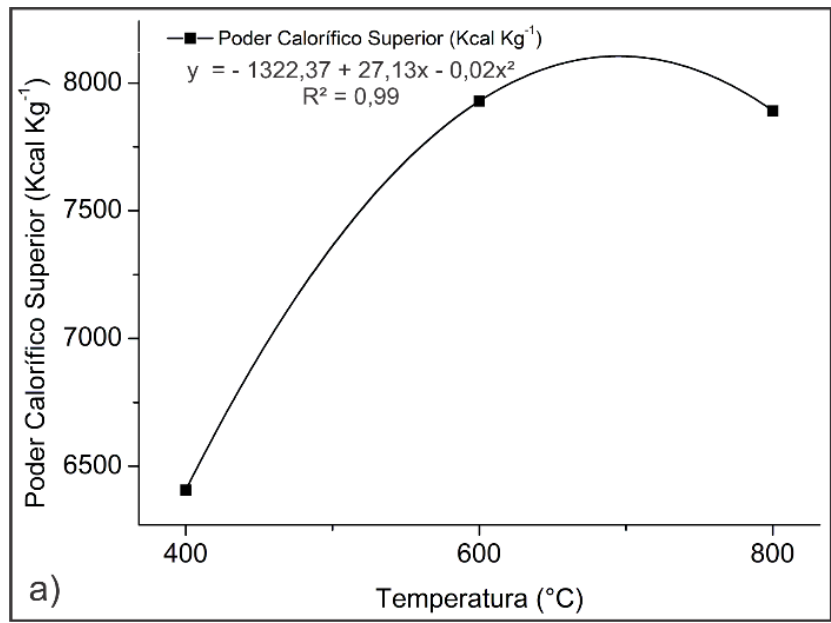

Figura 3 - Desempenho do poder calorífico superior (a) e densidade energética (b) em três temperaturas finais de pirólise (400, 600 e $\left.800^{\circ} \mathrm{C}\right)$.

O poder calorífico superior (PCS) sofreu uma pequena redução quando atingiu a temperatura de $800^{\circ} \mathrm{C}$, esse comportamento pode ser justificado pelo aumento do teor de cinzas. A elevação do teor de cinzas contribui para uma redução da eficiência energética, uma vez que afeta negativamente o poder calorifico (CUPERTINO et al., 2020). Xing et al. (2019), afirmam que o fator que determina um maior poder calorífico é o teor de cinzas, o que é elucidado pelo resultado encontrado. Mesmo com a redução do PCS, nota-se que os resultados de densidade energética tiveram um aumento significativo com a elevação de temperatura, variando $0,5 \%$ de 400 à $800^{\circ} \mathrm{C}$, sendo justificado pela densidade a granel utilizada para obtenção desse parâmetro.

Silva et al. (2016), em trabalhos com clones de Eucalyptus, observaram resultados similares aos teor de cinzas nos tratamentos com maiores proporções. Isso indica que a matéria-prima em estudo é adequada para uso energético, pois ao final do processo de combustão, as cinzas geradas resultarão em menos problemas de incrustações (VASSILEV et al., 2017, STRANDBERG et al., 2018).

A Figura 3 mostra os resultados de poder calorífico e densidade energética dos finos de carvão vegetal produzidos em diferentes temperaturas de pirólise.

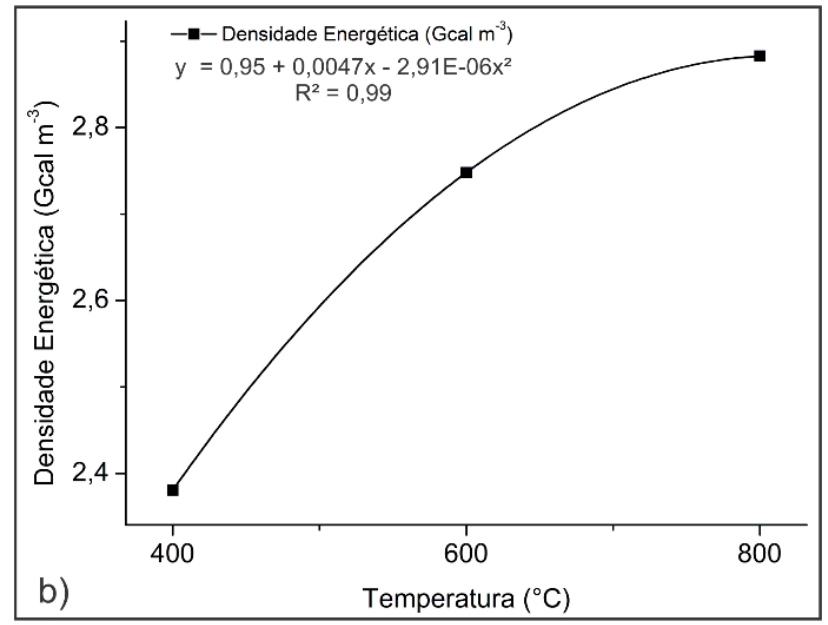

obtidos neste estudo. Uma vez que, a densidade energética é um importante parâmetro para combustíveis sólidos, pois, avalia a quantidade de energia armazenada em um determinado volume de um material. Diante dessas características, estudos afirmam que a adição de finos de carvão vegetal na produção de combustíveis compactados é uma excelente alternativa para aumentar a densidade energética, sendo justificado pela elevada quantidade de energia armazenada no material (DELATORRE et al., 2020).

Os resultados obtidos pela correlação de Pearson apresentaram notáveis correlações negativas e positivas entre as características físicas e químicas consideradas importantes para se determinar as influências entre variáveis e a temperatura de pirólise (Figura 4). 


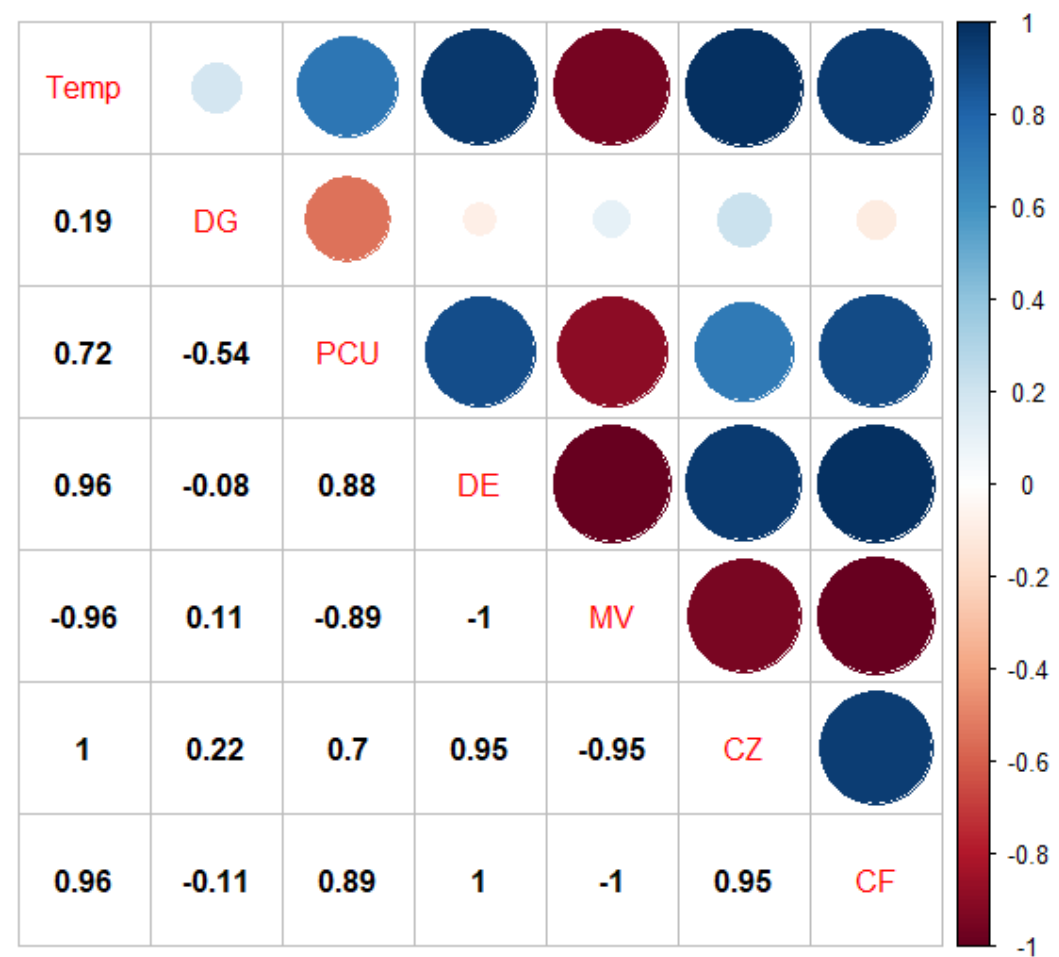

Figura 4 - Matriz de correlação das análises dos finos de carvão vegetal em três temperaturas finais de pirólise. Onde: Temp = temperatura; $\mathrm{DG}=$ densidade a granel; $\mathrm{PCU}=$ poder calorífico útil; $\mathrm{DE}=$ densidade energética; $\mathrm{MV}=$ materiais voláteis; $\mathrm{CZ}=$ teor de cinzas; $\mathrm{CF}=$ teor de carbono fixo.

Em relação a temperatura de pirólise e materiais voláteis nota-se uma correlação negativa. Esse comportamento foi similar ao encontrado por Klingenberg et al. (2020), comprovando o caráter orgânico desses compostos. O teor de carbono fixo, teor de cinzas, poder calorífico útil e densidade energética tiveram correlação positiva com o aumento da temperatura. Silva et al. (2018), afirma que existe um acréscimo no teor de carbono fixo à medida que se eleva a temperatura final de pirólise, influenciando positivamente no poder calorífico superior e consequentemente no poder calorífico útil. Esse último parâmetro é excelente para avaliar o potencial energético de um material, pois dar um indicativo da energia contida, possibilitando uma melhor aplicabilidade da matéria prima (DIAS JÚNIOR et al., 2015). Couto et al. (2015) afirmam que maiores temperaturas finais de pirólise resultam em um carvão vegetal com maior teor de cinzas, elucidando o resultado obtido. O comportamento da densidade energética com a elevação de temperatura está relacionado com a influência do poder calorífico utilizado para obtenção desse parâmetro.

Diante da atual demanda por novas metodologias de fontes renováveis para utilização para geração de bioenergia, os resultados desta pesquisa podem ser utilizados como ponto de partida para pesquisas posteriores. Recomenda-se que mais pesquisas sobre o potencial energético dos finos de carvão vegetal sejam realizadas.

\section{CONCLUSÃO}

Evidencia-se que os finos de carvão vegetal de $800^{\circ} \mathrm{C}$ se mostraram viável para fins energético, apesar de em $600^{\circ} \mathrm{C}$ apresentar uma queda no poder calorífico superior devido ao aumento do teor de cinzas. $\mathrm{Em} 800^{\circ} \mathrm{C}$ teremos maior estoque de energia, em um menor espaço. Se faz necessário estudos mais aprofundados, para o entendimento de tal matériaprima e, possíveis melhorias no processo.

\section{REFERÊNCIAS}

AMERICAN SOCIETY FOR TESTING AND MATERIAL - ASTM. D1762-84: Standard Test Method for Chemical Analysis of Wood Charcoal, 2007.

ANDRADE, C. R. Tratamento térmico da madeira contida nos resíduos sólidos urbanos visando sua adequação para uso energético. 2017. 85f. Tese (Doutorado em Recursos Florestais). Escola Superior de Agricultura Luiz de Queiroz, Universidade de São Paulo, Piracicaba.

ASSOCIAÇÃO BRASILEIRA DE NORMAS TÉCNICAS. NBR 6922: Carvão vegetal - ensaios fisícos determinação da massa específica do carvão vegetal. Rio de Janeiro, 1981. 2p.

ASSOCIAÇÃO BRASILEIRA DE NORMAS TÉCNICAS. NBR 8633: carvão vegetal - determinação do poder calorífico. Rio de Janeiro, 1984. 13p. 
ASSOCIAÇÃO BRASILEIRA DE NORMAS TÉCNICAS. NBR 8633: carvão vegetal - determinação do poder calorífico. Rio de Janeiro, 1984. 13p.

ASSOCIAÇÃO BRASILEIRA DE NORMAS TÉCNICAS. NBR 9165: determinação relativa aparente, relativea verdadeira e porosidade. Rio de Janeiro: ABNT, $1985,8 \mathrm{p}$.

BRITO, J. O. Expressão da produção florestal em unidades energéticas. Congresso florestal Panamericano, 7, 1993, Curitiba, Anais...Curitiba, p.280-82, 1993.

COUTO, Allan Motta; TRUGILHO, Paulo Fernando; NAPOLI, Alfredo; LIMA, José Tarcísio; SILVA, José Reinaldo Moreira da; PROTÁSIO, Thiago de Paula. Qualidade do carvão vegetal de Eucalyptus e Corymbia produzido em diferentes temperaturas finais de carbonização. Scientia Forestalis, v. 43, n. 108, p. 817831, 1 dez. 2015.

CUPERTINO, G. F. M.; SOUZA, N. D.; DELATORRE, F. M.; Junior A. J. S.; DIAS JÚNIOR, A. F. Resíduos madeireiros urbanos: abordagem técnica para a sua utilização como fonte de energia renovável e sustentável. In: Paulo Roberto Megna Francisco. (Org.). Estudos e Inovações na Engenharia e Agronomia. 2ed.Campina Grande: EPTEC, 2020, p. 52-60.

DELATORRE, F. M.; CUPERTINO, G. F. M.; SILVA, Á. M.; SANTOS JÚNIOR, A. J.; MESQUITA, J. G.; DIAS JÚNIOR, A. F. POTENCIAL ENERGÉTICO DOS FINOS DE CARVÃO VEGETAL. Engenharia Florestal: Desafios, Limites e Potencialidade, p. 639$653,2020$.

DIAS JÚNIOR, A. F.; ANDRADE, A. M.; SOARES, V. W.; COSTA JÚNIOR, D. S.; FERREIRA, D. H. A. A.; LELES, P. S. S.. Potencial energético de sete materiais genéticos de Eucalyptus cultivados no Estado do Rio de Janeiro. Scientia Forestalis, v. 43, n. 108, p. 833-843, 1 dez. 2015.

DIAS JÚNIOR, A. F.; SUUCHI, M. A.; SANT'ANNA NETO, A.; SILVA, J. G. M.; SILVA, Á. M.; SOUZA, N. D.; PROTÁSIO, T. P.; BRITO, J. O.. Blends of charcoal fines and wood improve the combustibility and quality of the solid biofuels. Bioenergy Research, 15 ago. 2020.

DIAS JÚNIOR, A. F.; SUUCHI, M. A.; SANT'ANNA NETO, A.; SILVA, J. G. M.; SILVA, Á. M.; SOUZA, N. D.; PROTÁSIO, T. P.; BRITO, J. O.. Blends of charcoal fines and wood improve the combustibility and quality of the solid biofuels. Bioenergy Research, 15 ago. 2020.

EPE - Empresa de Pesquisa Energética -. Balanço Energético Nacional - 2019. Disponível em: https://www.epe.gov.br/sites-pt/publicacoes-dadosabertos/publicacoes/PublicacoesArquivos/publicacao479/topico-528/BEN2020_sp.pdf. Acesso em: $22 \mathrm{dez}$. 2020.
FAO - Food And Agriculture Organization. The charcoal transition: greening the charcoal value chain to mitigate climate change and improve local livelihoods 2016. Disponível em: <http:// www.fao.org/3/ai6935e.pdf >. Acesso em: 23 dez. 2020.

FIGUEIREDO, M. E. O.; LONGUE JÚNIOR, D.; PEREIRA, A. K. S.; CARNEIRO, A. C. O.; SILVA, C. M. S. POTENCIAL DA MADEIRA DE Pterogyne nitens Tul. (MADEIRA-NOVA) PARA PRODUÇÃO DE CARVÃO VEGETAL. Ciência Florestal, v. 28, n. 1, p. 420-431, 2 abr. 2018.

IBÁ - Indústria Brasileira de Árvores. Relatório 2019. Disponível em:<https://iba.org/datafiles/ publicacoes/relatorios/iba-relatorioanual2019.pdf $>$.

Acesso em: 21 dez. 2020.

KIRUKI, H. M.; ZANDEN, E. H. van Der; KARIUKI, P.; VERBURG, P. H. The contribution of charcoal production to rural livelihoods in a semi-arid area in Kenya. Environment, Development And Sustainability, v. 22, n. 7, p. 6931-6960, 25 nov. 2019.

KLINGENBERG, D.; NOLASCO, A. M.; DIAS JÚNIOR, A. F.; CANDATEN, L.; CAVALCANTE, A. K. L.; SOUZA, E. C. de. Potencial energético de resíduos madeireiros de uma floresta tropical urbana. Research, Society and Development, v. 9, n. 9, p. 1-21, 2020. DOI: 10.33448/rsd-v9i9.7478.

MARTINS, M. P.; BENÍCIO, E. L.; DIAS JÚNIOR, A. F.; ALMEIDA, R. B.; CARVALHO, A. M.; YAMAJI, F. M. Produção e avaliação de briquetes de finos de carvão vegetal compactados com resíduo celulósico proveniente da indústria de papel e celulose1. Revista Árvore, v. 40, n. 1, p. 173-180, fev. 2016.

MME - Ministério de Minas e Energia. Resenha Energética Brasileira 2019. Disponível em: $<$ http://www.eletronuclear.gov.br/Imprensa-eMidias/Documents/Resenha\%20Energ\%C3\%A9tica\%202018\%20-MME.pdf>. Acesso em: 20 dez. 2020.

OLIVEIRA, A. C.; CARNEIRO, A. D. C. O.; VITAL, B. R.; ALMEIDA, W.; PEREIRA, B. L. C.; CARDOSO, M. T. Parâmetros de qualidade da madeira e do carvão vegetal de Eucalyptus pellita F. Muell. Scientia Forestalis, Piracicaba, v. 38, n. 87, p. 431-439, set. 2010.

PROTÁSIO, T. P.; NEVES, T. A.; REIS, A. A.; TRUGILHO, P. F. Efeito da idade e clone na qualidade da madeira de Eucalyptus spp. visando à produção de bioenergia. Ciência Florestal, Santa Maria, v. 24, n. 2, p. 465-477, 2014.

PROTÁSIO, Thiago de Paula; SCATOLINO, Mário VASSILEV, Stanislav V.; VASSILEVA, Christina G.. Composition, properties and challenges of algae biomass for biofuel application: an overview. Fuel, v. 181, p. 1-33, out. 2016. 
RODRIGUES, T.; BRAGHINI JUNIOR, A. Technological prospecting in the production of charcoal: a patent study. Renewable And Sustainable Energy Reviews, v. 111, p. 170- 183, set. 2019.

REIS, A. A.; PROTÁSIO, T. P.; MELO, I. C. N. A.; TRUGILHO, P. F.; CARNEIRO, A. C. Composição da madeira e do carvão vegetal de Eucalyptus urophylla em diferentes locais de plantio. Pesquisa Florestal Brasileira, Colombo, v. 32, n. 71, p. 277-290, 2012.

REIS, A. A.; MELO, I. C. N. A.; PROTÁSIO, T. P.; TRUGILHO, P. F.; CARNEIRO, A. C. O. Efeito de local e espaçamento na qualidade do carvão vegetal de um clone de Eucalyptus urophylla S. T. Blake. Floresta e Ambiente, v. 19, n. 4, p. 497-505, 2012.

SILVA, Macksuel Fernandes da. Propriedades energéticas da biomassa e do carvão vegetal de espécies de bambu e clones de eucalipto. 2016. 69 f. Dissertação (Mestrado) Curso de Mestre em Agronomia, Universidade Federal de Goiás, Goiânia, 2016.

SILVA, L. L. H.; OLIVEIRA, E.; CALEGARI, L.; PIMENTA, M. A. C.; PIMENTA, A. S.; DANTAS, M. K. L. Características energéticas do carvão vegetal de aroeira (Myracrodruon urundeuva Allemão) e Leucena (Leucaena leucocephala (Lam.) R. de Wit). Ciência Florestal, v. 28, n. 1, p. 412-419, 2 abr. 2018

SIQUEIRA, L. C. G. Estudo das emissões de compostos orgânicos persistentes (pops) tóxicos de formação não intencional provenientes da produção de carvão vegetal no estado de São Paulo. Universidade de São Paulo. Relatório de pós-doutorado. São Paulo. p. 1-184. 2015.

SOMERVILLE, M.; JAHANSHAHI, S. The effect of temperature and compression during pyrolysis on the density of charcoal made from Australian eucalypt wood. Renewable Energy, v. 80, p. 471-478, ago. 2015.

STRANDBERG, Anna; THYREL, Mikael; SKOGLUND, Nils; LESTANDER, Torbjörn A.; BROSTRÖM, Markus; BACKMAN, Rainer. Biomass pellet combustion: cavities and ash formation characterized by synchrotron $\mathrm{x}$-ray micro-tomography. Fuel Processing Technology, v. 176, p. 211-220, jul. 2018.
TRUGILHO, Paulo Fernando; SILVA, Dimas Agostinho da. Influência da temperatura final de carbonização nas características físicas e químicas do carvão vegetal de jatobá (Himenea courbaril L.). Scientia Agraria, v. 2, n. 1, p. 45-53, 31 dez. 2001.

VALE, A. T.; BRASIL, M. A. M.; CARVALHO, C. M.; VEIGA, R. A. Produção de energia do fuste de Eucalyptus grandis hill ex-maiden e Acacia mangium willd em diferentes níveis de adubação. Cerne, v.6, n.1, p. 83-88, 2000.

VALE, A. T.; DIAS, I. S.; SANTANA, M. A. E. Relação entre as propriedades químicas, físicas e energéticas da madeira de cinco espécies do cerrado. Ciência Florestal, Santa Maria, v. 20, n. 1, p. 137-145, mar. 2010.

Vanoli; ARAðJO, Ana Clara Caxito de; OLIVEIRA, Ana Flávia Cunha Fernandes de; FIGUEIREDO, Izabel Cristina Rodrigues de; ASSIS, Maíra Reis de; TRUGILHO, Paulo Fernando. Assessing Proximate Composition, Extractive Concentration, and Lignin Quality to Determine Appropriate Parameters for Selection of Superior Eucalyptus Firewood. Bioenergy Research, v. 12, n. 3, p. 626-641, 1 jul. 2019.

VASSILEV, Stanislav V.; VASSILEVA, Christina G.; SONG, Yun-Cai; LI, Wen-Ying; FENG, Jie. Ash contents and ash-forming elements of biomass and their significance for solid biofuel combustion. Fuel, v. 208, p. 377-409, nov. 2017.

WANG, S.; DAI, G.; YANG, H.; LUO, Z. Lignocellulosic biomass pyrolysis mechanism: a state-of-the-art review. Progress In Energy And Combustion Science, v. 62, p. 33-86, set. 2017.

XING, J.; LUO, K.; WANG, H.; GAO, Z.; FAN, J. A comprehensive study on estimating higher heating value of biomass from proximate and ultimate analysis with machine learning approaches. Energy, v. 188, p. 1-11, dez. 2019. 